Military Technical College

Kobry El-Kobbah,

Cairo, Egypt

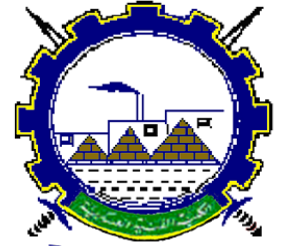

I.C.E.E.2016 $8^{\text {th }}$ International Conference

on

Chemical \& Environmental

Engineering

19 - 21 April 2016

\title{
RA-1
}

\section{Characterization and drug delivery properties of gamma irradiated poly (vinyl alcohol)/methylcellulose (PVA/MC) blends}

Abdel Wahab M. El-Naggar ${ }^{1}$, Magdy M. Senna ${ }^{1}$, Tahia A. Mostafa ${ }^{2}$, Reham H. Helal ${ }^{1}$,

\begin{abstract}
In this work, polymer blends based on poly(vinyl alcohol) (PVA) and different ratios (5 and $10 \mathrm{wt} \%$ ) of methylcellulose (MC) were prepared into films by solution casting using water as a common solvent, and gamma irradiated at different doses. The blends before and after gamma irradiation were loaded with Doxycycline hyclate (DOX-h) as drug model. The effect of DOX-h drug on the chemical and physical properties was first investigated in terms of gel content, swelling and surface morphology by scanning electron microscopy (SEM). The gamma irradiated PVA/MC blends was evaluated for the possible use in drug delivery systems. In this respect, the release profiles of DOX-h from PVA/MC were investigated. It was found that the accumulated drug release from the blends increases with time to reach $\sim 60 \%$ after $1 \mathrm{~h}$ at $\mathrm{pH}$ of 2 compared to $\sim 100 \%$ at $\mathrm{pH}$ of 8.
\end{abstract}

Keywords: Poly (vinyl alcohol); Methylcellulose; Gamma Radiation; Gel fraction; Swelling characters; Drug delivery

${ }^{1}$ Radiation Chemistry Department, National Center for Radiation Research and Technology, B.O. Box 29 Nasr City, Atomic Energy Authority, Cairo Egypt.

${ }^{2}$ Chemistry Department, College for Girls, Ain Shams University, Cairo, Egypt 


\section{Military Technical College \\ Kobry El-Kobbah, Cairo, Egypt}

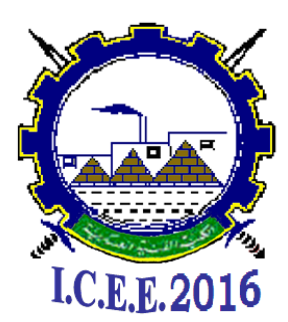

$8^{\text {th }}$ International Conference

on

Chemical \& Environmental Engineering

$19-21$ April 2016

\section{Introduction}

There has been an increasing interest in blending different homopolymers to obtain new products having some of the characteristic properties of each component. The demand for compatible blends may constitute one of the most important attractive trends in the field of polymer blends. This is because a wide variety of properties can be tailored from the simple physical combination of two compatible polymeric components. Radiation technique may be considered a very convenient tool for the modification of polymer blends through compatibilization, crosslinking, grafting, and degradation [1-5].

Poly(vinyl alcohol) (PVA) is a well known biologically friendly, non-toxic, semicrystalline synthetic polymer with properties such as water solubility, biodegradability and biocompatibility, and therefore, it finds uses in a broad spectrum of applications [6]. Methylcellulose (MC) is one of the best-known modified cellulose, in which some of the hydroxyl groups are replaced by methoxyl groups. The conversion of some of the hydroxyl groups of cellulose into hydrophobic substitutions attenuates the hydrogen bonding, thus decreasing the crystallinity and increasing the water solubility $[7]$.

Doxycycline, a semi-synthetic derivative of oxytetracycline is a potent antibacterial drug commonly used as doxycycline hyclate (DOX-h) and used for both in humans and animals treatments [8]. The antibacterial mechanism is mainly regarded as timedependant and DOX-h is a relatively inexpensive antibacterial drug, potent and possesses a broad-spectrum antibacterial action [9]. In this regard, a poloxamer-based matrix was used to produce a long-acting injectable preparation (DOX-h) and its serum concentrations vs. time profile was investigated after its s.c. injection to calves. It was found that the DOX-h showed the greatest values for bioavailability (602\%); maximum serum concentration $\left(\mathrm{C}_{\max }\right)$ of $1.99 \mathrm{lg} / \mathrm{mL}$ with a time to reach $\left(\mathrm{T}_{\max }\right)$ of $25 \mathrm{~h}$ and an elimination half-life of 40.81h. DOX-h loaded poly(ethylene glycol) hydrogels for healing vesicant induced ocular wounds healing in rabbits [10]. In vitro doxycycline release from the hydrogel disks $(0.25 \% \mathrm{w} / \mathrm{v})$ was found to be biphasic with release half times of 12 and $72 \mathrm{~h}$, respectively, with $80-100 \%$ released over a 7 -day period. The effects of low-doses of DOX-h on the cytokine production by human monocytic cells challenged with the periodontal pathogen Aggregatibacter actinomycetemcomitans, for up to $6 \mathrm{~h}$ in which the simultaneous regulation of 12 cytokines was measured by a Human Cytokine Array Kit [11]. The results indicated that DOX-h acts as an anti-inflammatory agent in human monocytic cells stimulated with Aggregatibacter actinomycetemcomitans. Strontium substituted calcium phosphate cement (CPC) loaded with (DOX-h) was used to confirm the effect of strontium substitution on antibiotic 
Military Technical College

Kobry El-Kobbah, Cairo, Egypt

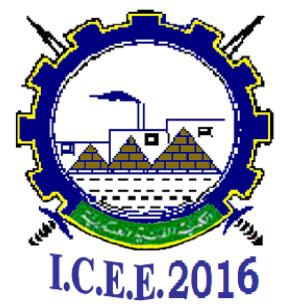

$8^{\text {th }}$ International Conference

on

Chemical \& Environmental Engineering

$19-21$ April 2016

delivery [12]. It was concluded that strontium substitution in secondary calcium phosphate cements improved the efficiency for DOX-h adsorption and release. It was reported that taking (DOX-h) drug the night prior to surgery may resulted in adequate absorption and evacuation (D\&E) with better tolerance [13]. In this study, they enrolled 40 women into a double-blind randomized comparison of (DOX-h) $200 \mathrm{mg}$ given $4 \mathrm{~h}$ before D\&E (Group 1) vs. the night prior to D\&E with dinner (Group 2).

Polymeric materials, particularly those based on natural polymers, are suitable to serve as carriers and delivery in external conditions [14-21]. In the present work, poly(vinyl alcohol) (PVA) as a hydrophilic polymer was blended with low ratios of the methylcellulose (MC) and exposed to gamma irradiation; potentially these blends could be used in drug delivery field. Doxycycline hyclate (DOX-h) drug was used as a model drug. In this contest, the effect of loading (DOXY-h) drug on some properties either before or after gamma irradiation was studied.

\section{Experimental}

\subsection{Materials}

Poly (vinyl alcohol) (PVA) used in this study was a laboratory-grade chemical and purchased from Backer Chemical Co., USA. It was in the form of powder, fully hydrolyzed and has an average molecular weight of $125,000 \mathrm{~g} / \mathrm{mol}$. Methylcellulose (MC) was a laboratory-grade chemical and purchased from Sigma Company, Canada. Doxycycline hyclate (DOX-h) as an antibacterial agent was used to treat a wide variety of bacterial infections, and this medication is known as a tetracycline antibiotic. The empirical formula is $\left.\left(\mathrm{C}_{22} \mathrm{H}_{24} \mathrm{~N}_{2} \mathrm{O}_{8} \bullet \mathrm{HCI}\right)_{2} \cdot \mathrm{C}_{2} \mathrm{H}_{6} \mathrm{O} \cdot \mathrm{H}_{2} \mathrm{O}\right)$. The chemical structure is shown in Fig.1. The drug was a gift from Tabuk Pharmaceutical, October city, Egypt.

\subsection{Preparation of poly(vinyl alcohol) /methylcellulose blends}

The preparation of poly(vinyl alcohol)/methylcellulose (PVA)/(MC) blends was carried out as follows: Aqueous polymer solutions (10 wt\%) of PVA and MC were prepared by dissolving the required weight of polymer powders in water and heating at $80^{\circ} \mathrm{C}$ under continuous stirring. The blend films were obtained by solution casting of polymer blends on a glass plate and air-drying for $72 \mathrm{~h}$ at room temperature.

\subsection{Gamma Irradiation}

Irradiation to the required doses was carried out in the Co-60 gamma cell at a dose rate of $2.4 \mathrm{kGy} / \mathrm{h}$ in air. The gamma cell facility was installed at the National Center for 
Military Technical College

Kobry El-Kobbah, Cairo, Egypt

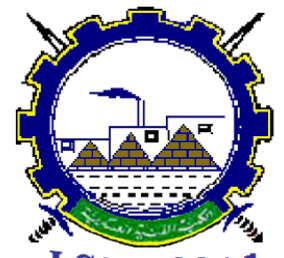

I.C.E.E. 2016 $8^{\text {th }}$ International Conference

on

Chemical \& Environmental Engineering

19 - 21 April 2016

Radiation Research and Technology, Cairo, Egypt. The exposure time was adjusted to achieve the required absorbed doses.

\subsection{Gel fraction}

Samples of the prepared polymer blends were accurately weighed $\left(\mathrm{W}_{\mathrm{o}}\right)$ and then extracted with distilled water using a soxhlet system and then dried in a vacuum oven at $80^{\circ} \mathrm{C}$ to a constant weight $\left(\mathrm{W}_{1}\right)$. The gel fraction was calculated according to the following equation:

Gel fraction $(\%)=\left(\mathrm{W}_{1} / \mathrm{W}_{\mathrm{o}}\right) \times 100$

\subsection{Swelling characters}

The swelling studies were conducted on PVA/MC blends as a function of irradiation dose. A known dry weight of insoluble blend $\left(\mathrm{W}_{\mathrm{d}}\right)$ was immersed in water up to $24 \mathrm{~h}$ at $25^{\circ} \mathrm{C}$ for each dose, the sample was removed and blotted on filter paper to remove excess water and weighed $\left(\mathrm{W}_{\mathrm{s}}\right)$, in which the percentage swelling was calculated according to the following equation:

Swelling $(\%)=\left[\left(\mathrm{W}_{\mathrm{s}}-\mathrm{W}_{\mathrm{d}}\right) / \mathrm{W}_{\mathrm{d}}\right] \times 100$

\subsection{Drug release experiment}

For the investigation of drug release properties of PVA/MC blends, Doxycycline hyclate (DOX-h) was used as a model drug. Dry sample pieces $(0.5 \mathrm{~g})$ of blends were loaded with DOX-h drug by immersion into aqueous solutions of drug $(60 \mathrm{mg} / \mathrm{l})$ for $24 \mathrm{~h}$. The release of DOX-h from blends was measured by placing the blends loaded with drug in a vessel containing $20 \mathrm{ml}$ of different buffer solutions at a constant shaking rate. At each time interval, aliquots of $3 \mathrm{ml}$ were drawn from the medium to follow the release of DOX-h and returned into the vessel to keep the solution volume constant. DOX-h release was determined by a spectrophotometeric method using a Unicam $8625 \mathrm{UV} /$ visible spectrophotometer at $\lambda_{\max }$ of $345 \mathrm{~nm}$ and expressed ad $\mathrm{mg} / \mathrm{l} / \mathrm{gram}$ polymer.

\section{Results and discussion}

\subsection{Effect of gamma radiation on PVA/MC blends}

PVA and MC are water-soluble polymers with, theoretically, have no functional groups required to achieve miscibility and the competition of hydrogen bonding. Although, MC 


\section{Military Technical College \\ Kobry El-Kobbah, Cairo, Egypt}

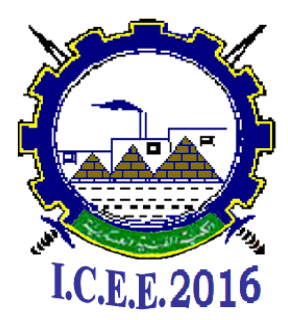

$8^{\text {th }}$ International Conference

on

Chemical \& Environmental Engineering

$19-21$ April 2016

is a water-soluble polymer that give a clear and visually transparent solution, all attempts to form cast films failed. However, when PVA/MC blend solutions with low MC ratios were prepared, good films were obtained and appeared transparent to visual observation. In this regard, when the ratio of $\mathrm{MC}$ in the polymer blends were increased beyond $10 \%$, phase separation was observed and the transparency no longer occurred. In addition to the free radical formation on the backbone of polymers, it was reported that the polymerization and crosslinking occurs by the products of the radiolysis of water, which is present in appropriate quantities, as reported in the very early stage of radiation chemistry according to the following equation [22]:

$$
\mathrm{H}_{2} \mathrm{O} \stackrel{\text { Gamma irradiation }}{\longrightarrow} \mathrm{e}_{\mathrm{aq}}^{-} ; \mathrm{H} ; \mathrm{H}_{2} \mathrm{O}_{2} ; \mathrm{H}_{2}
$$

The mechanism of crosslinking of PVA in aqueous solution by gamma radiation can be briefly outlined as follows: (1) the polymer PVA and the solvent $\mathrm{H}_{2} \mathrm{O}$ absorb gamma radiation resulting in the formation of the radicals $-\left(-\mathrm{CH}^{\bullet}-\mathrm{CH}^{\bullet}-\mathrm{OH}-\right)_{\mathrm{n}}, \mathrm{HO}^{\bullet}$ and $\mathrm{H}^{\bullet}$. The transfer of radicals from water to polymer increases the concentration of PVA radicals and increases the rate of crosslinking and gelation and (2) Two polymer radicals with "n" and " $\mathrm{m}$ " repeat units combine to form a crosslinked network structure as shown in Fig.2.

3.2. Characterization of PVA/MC blends loaded with DOX-h drug

In this study, the effect of loading DOX-h drug on the physico-chemical properties of the $\mathrm{PVA} / \mathrm{MC}$ blends was first investigated. In this contest, the effect on gel fraction (\%) and swelling characters were investigated, whereas surfaces morphology was examined by scanning electron microscopy (SEM).

\subsubsection{Gel content}

The gel fraction of PVA/MC blends loaded with $1 \%$ of (DOX-h) drug and PVA/MC blends free of drug, measured at different $\mathrm{pH}$ values, gamma irradiated at different doses is shown in Fig.3. It can be seen that, the gel fraction decreases with increasing methylcellulose (MC) ratio, while the gel fraction was increased with increasing irradiation dose up to $30 \mathrm{kGy}$ and then tends to level off at $40 \mathrm{kGy}$. It is known that the polymer blends respond to the presence of water and $\mathrm{pH}$. In this regard, the gel fraction (\%) was found to increase with increasing the $\mathrm{pH}$ value. On the other hand, the addition of $1 \%$ of (DOX-h) drug has a clear effect on the gel fraction compared to the gel fraction of PVA/MC blends free of drug. In this regard, it can be seen that the gel fractions (\%) of PVA/MC blends having 5 and 10\% was increased, while it increases with increasing the irradiation dose up to $40 \mathrm{kGy}$. Also, the gel fraction was found to increase with increasing the $\mathrm{pH}$ values from 3 to 9 . The increase in gel fraction due to the addition of 
Military Technical College

Kobry El-Kobbah, Cairo, Egypt

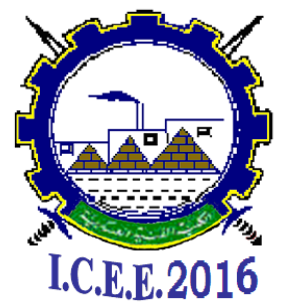

$8^{\text {th }}$ International Conference on

Chemical \& Environmental Engineering

$19-21$ April 2016

DOX-h drug could be explained as due the formation of hydrogen bonds with the hydroxyl groups of PVA and those on the chemical structure of drug. This state of affairs would facilitate the exposure of blends to gamma irradiation and hence increase the crosslinking of PVA component.

\subsubsection{Swelling characters}

Figures 4-5 show the swelling (\%) measured at different $\mathrm{pH}$ values of PVA/MC blends, before and after loading with $1 \%$ of (DOX-h) drug, gamma irradiated at different doses. Based on these figures and comparing with those figures of PVA/MC blends free of drug, few points may be concluded:

(1) The PVA/MC blends containing relatively low ratio (5\%) of MC displayed higher swelling (\%) than the blend containing higher ratio $(10 \%)$ of $\mathrm{MC}$. This is due the higher crosslinking of PVA component. However, the blends loaded with drug showed swelling (\%) lower than the blends free of drug. This is due to the presence of DOX-h drug, which impedes the penetration of water.

(2) In general, the swelling (\%) was considerably decreased with increasing irradiation dose in accordance with the gel fraction, in which the crosslinking led to the restriction of the water swelling [22].

(3) The effect of different values $\mathrm{pH}$ on the swelling is clear, in which the PVA/MC blends displayed $\mathrm{pH}$-sensitive swelling character. In this regard, the swelling increased with the $\mathrm{pH}$ value from 7 or 9, regardless of PVA/MC ratio [23]. However, the swelling of PVA/MC (95/5\%) blend was higher than that for PVA/MC (90/10\%) blend, regardless of $\mathrm{pH}$ value. The swelling (\%) decreased with increasing irradiation dose, regardless of $\mathrm{pH}$ value. The lower swelling associated with increasing irradiation dose is attributed to the increase of crosslinking density, in which the chains are compact and thus blocks the voids for the diffusion of water molecules [24].

\subsubsection{Surface morphology of blends loaded with drug}

The scanning electron microscopy (SEM) was used to examine the effect of loading drug on the surface morphology of PVA/MC blends, gamma irradiated at different doses, and loaded with $1 \%$ of DOX-h drug, as shown in Fig.6. In general, the blends loaded with DOX-h drug showed a rough surface. However, it can be seen that the presence of MC had a great effect on the surface morphology of the blends loaded with drug. While, the 
Military Technical College

Kobry El-Kobbah, Cairo, Egypt

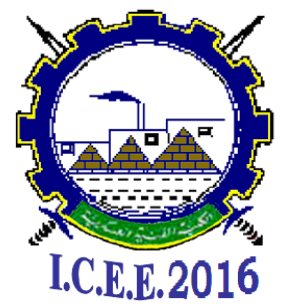

$8^{\text {th }}$ International Conference

on

Chemical \& Environmental Engineering

$19-21$ April 2016

blends containing relatively low ratio of MC showed a micro porous surface morphology, the blends containing higher ratios of PVA showed a surface characterized with large continuous wrinkles. The presence of wrinkles in the PVA/MC blends, loaded with drug, and the smooth surface of the PVA/MC blends, without drug, may be explained as follows. The formation of wrinkles may be attributed to the formation of hydrogen bonding between the hydroxyl groups of DOX-h drug and the carboxyl groups of crosslinked PVA in the network structure.

\subsection{Drug delivery studies}

DOX-h was selected as drug model to evaluate the PVA/MC blends for the possible use as controlled drug release systems. In order to determine the release of DOX-h, a standard calibration curve representing the absorbance of different concentrations of Doxycycline hyclate was first constructed as shown in Fig.7. From this relation, a concentration of unknown sample can be determined. The relation correlating this curve is calculated to be:

Absorbance $=0.003473$ (concentration, $\mathrm{mg} / \mathrm{l}$ )

Concentration $=$ Absorbance $/ 0.003473$

\subsubsection{Effect of irradiation dose}

The release of DOX-h drug from polymer blends loaded with drug occurs after water has penetrated the polymeric networks and this is followed by diffusion along the aqueous medium. Thus, drug release is related to the swelling characters of polymer blends. The release of drug release from PVA/MC (95/5\%) blend was selected to study the effect of gamma irradiation dose. Figure 8 shows the accumulated release of DOX-h drug, at room temperature and $\mathrm{pH} 7$, at different time intervals, from $\mathrm{PVA} / \mathrm{MC}(95 / 5 \%)$ blends, gamma irradiated at different doses. It is clear that the accumulated release increases with increasing time of release. Meanwhile, the accumulated release was found to reach maximum value at a dose of $10 \mathrm{kGy}$ of gamma irradiation; however, by further increase of dose the release tends to reach equilibrium. The decrease of the accumulated release of DOX-h drug associated with increasing dose is directly related the compact structure created due to the crosslinking of PVA and hence closes the voids and restricts the release of drug. 
Military Technical College

Kobry El-Kobbah, Cairo, Egypt

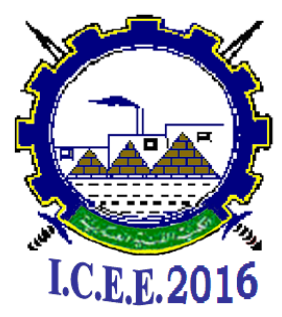

$8^{\text {th }}$ International Conference on

Chemical \& Environmental Engineering

$19-21$ April 2016

\subsubsection{Effect of $\mathrm{pH}$ values}

Figure 9 shows the accumulated release of DOX-h drug, at room temperature and different $\mathrm{pH}$ values, from PVA/MC blends, gamma irradiated at a dose of $30 \mathrm{kGy}$. Based on these figures, two points can be withdrawn:

(1) In all cases, the release profile tends to reach equilibrium after $\sim 60 \mathrm{~min}$, regardless of blend composition or $\mathrm{pH}$ value. However, the release from PVA/MC $(95 / 5 \%)$ blend is much lower than that from PVA/MC (90/10\%) blend. This is attributed to the higher crosslinking density of blend reach of PVA than that of higher ratio of MC. The higher crosslinking density will restrict the diffusion of drug from the blend.

(2) The release profiles suggest that the drug release process from PVA/MC blends is a $\mathrm{pH}$-sensitive. The process of release is also related to the $\mathrm{pH}$-sensitivity of swelling characters as shown before, in which the swelling (\%) increased with increasing $\mathrm{pH}$ value. Thus, the high swollen blend, the low is release of drug and vice versa. This behaviour can be explained on the basis that in acidic medium, the hydrogen bonding between PVA/MC blends and drug along the networks undergoes hydrolysis resulting in more drug release. In conclusion, the $\mathrm{PVA} / \mathrm{MC}$ blends and $\mathrm{pH}$ of solution determine the different processes. In this contest, as the MC ratio decreases the swelling ratio, whereas the drug release decreased in acidic medium and increased in basic medium.

\subsubsection{Release Kinetics of DOX-h drug}

To study transport mechanism of Doxycycline hyclate drug from PVA/MC blends, the experimental data have been further analyzed according to the following equation [25].

$$
\mathbf{F}=\mathbf{W}_{\mathrm{t}} / \mathbf{W}_{\mathrm{e}}=\mathrm{Kt}^{\mathrm{n}} \quad \text { Or } \quad \ln \mathrm{F}=\ln \mathrm{K}+\mathbf{n} \ln \mathrm{t}
$$

\section{Where:}

F is the ratio between $\mathrm{W}_{\mathrm{t}}$ and $\mathrm{W}_{\mathrm{e}}$. $\mathrm{W}_{\mathrm{t}}$ and $\mathrm{W}_{\mathrm{e}}$ represent, respectively, the amount of drug released ( $\mathbf{m g} / \mathbf{g})$ at time $\mathbf{t}$ (seconds) and at equilibrium, $\mathbf{K}$ is a constant related to the properties of the drug delivery system, and $\mathbf{n}$ is the diffusion exponent, which characterizes the drug release mechanism.

(1) A value of $\mathbf{n}=\mathbf{0 . 5}$ indicates the drug release follows the Fickian diffusion.

(2) When $\mathbf{n}=\mathbf{1}$, case II transport occurs.

(3) When $\mathbf{0 . 5}<\mathbf{n}<\mathbf{1}$, an anomalous transport or non-Fickian occurs. 


\section{Military Technical College \\ Kobry El-Kobbah, Cairo, Egypt}

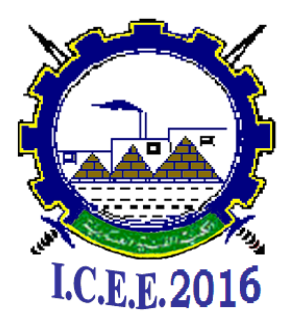

$8^{\text {th }}$ International Conference

on

Chemical \& Environmental Engineering

$19-21$ April 2016

The characteristics of a drug delivery system are evaluated using the first $70 \%$ release data. Figure 10 shows plots of $\ln \mathrm{F}$ against $\ln \mathrm{t}$ for the release of Doxycycline hyclate drug from PVA/MC (95/5\%) blends, gamma irradiated at different doses. Figure 11 shows plots of $\ln \mathrm{F}$ against $\ln \mathrm{t}$ plots for the release of Doxycycline hyclate drug from PVA/MC blends at different $\mathrm{pH}$ values, gamma irradiated at a dose of $30 \mathrm{kGy}$. The kinetic constants $(\mathrm{K})$, release exponents $(\mathrm{n})$, correlation coefficients $\left(\mathrm{r}^{2}\right)$ parameters are summarized in Tables 1-2. It is clear that the transport of Doxycycline hyclate follows non-Fickian range, in which $\mathrm{n}$ is higher than 0.5 and lower than 1 , however the $n$ values in acidic medium is higher than in basic medium. This clearly implies that the drugrelease process tends to become relaxation-controlled in the whole range of PVA/MC blends. This may be explained based on an increasing ratio of the MC, the network density of the blends decreased, thereby resulting in a slower relaxation of the invading molecules.

\section{References}

[1] J.S. Parka, J.W. Parkb, E. Ruckensteinc, Thermal and dynamic mechanical analyses of PVA/MC blend hydrogels, Polymer 42 (2001) 4271-4280.

[2] M. M. Senna, S. Salmieri, A. W. El-Naggar, A. Safrany, M. Lacroix, Improving the Compatibility of Zein/Poly(vinyl alcohol) Blends By Gamma Irradiation and Graft Copolymerization of Acrylic Acid, J. Agri. and Food Chem. 58 (2010) 4470-4476.

[3] H.M. Nizam El-Din and A. M. El-Naggar, Effect of Gamma Irradiation on the Physical Properties and Dyeability of Poly(vinyl butyral) blends with Polystyrene and Poly(ethylene glycol), Polymer Composites 29 (2008) 1364-1371.

[4] M. M. Senna, F. M. Hossam and A.M. El-Naggar, Compatibilization of low-density polyethylene/plasticized strarch blends by reactive compounds and electron beam irradiation, Journal of Applied Polymer Science 106 (2007) 4202.

[5] H. M. Nizam El-Din, A. M. El-Naggar, F. I. Ali, Thermal decomposition behavior of $\gamma$-irradiated poly(vinyl acetate)/poly(methyl methacrylate) miscible blends, Journal of Applied Polymer Science 99 (2006)1773.

[6] Anuj Kumar, Yuvraj Singh Negia, Nishi Kant Bhardwaj, Veena Choudhary. Synthesis and characterization of methylcellulose/PVA based porous composite, Carbohydrate Polymers 88 (2012) 1364- 1372.

[7] J.S. Park, J.W. Park, E. Ruckenstein, Thermal and dynamic mechanical analysis of PVA/MC blend hydrogels, Polymer 42 (2001) 4271-4280.

[8] Vargas E.strada, D., Gracia-Mora, J., Sumano, H., Pharmacokinetic study of an injectable long-acting parenteral formulation of doxycycline hyclate in calves,

[9] Research in Veterinary Science 84(2008) 477- 482. 
Military Technical College

Kobry El-Kobbah, Cairo, Egypt

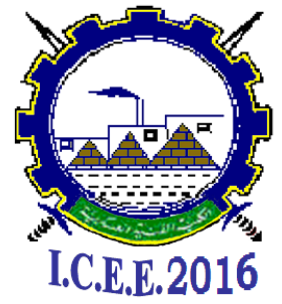

$8^{\text {th }}$ International Conference

on

Chemical \& Environmental Engineering

$19-21$ April 2016

[10] J.F. Prescott, J.D. Baggot and R.D. Walker, Antimicrobial Therapy in Veterinary Medicine, third ed. Iowa State University Press, Ames, Iowa, USA, pp. 275-289 (2000).

[11] S. SivaNaga, Anumolu, S. Andrea, DeSantis, R. Anupa, Menjoge, A. Rita, Hahn, A. John, Beloni, K. Marion,Gordon, J. Patrickanf, Sinko, Doxycycline loaded poly(ethylene glycol) hydrogels for healing vesicant-induced ocular wounds, Biomaterials 31 (2010) 964-974.

[12] N. Bostanci, B. Akgül, V. Tsakanika, R.P. Allaker, F.J. Hughes d, I.J. McKay,

[13] Effects of low-dose doxycycline on cytokine secretion in human monocytes stimulated with Aggregatibacter actinomycetemcomitans, Cytokine 56 (2011) 656661.

[14] M. Hamdan Alkhraisat, C. Rueda, J. Cabrejos-Azama, J. Lucas-Aparicio, F. Tamimi Mario, J. Torres Garca-Denche, L. Blanco Jerez, U. Gbureck, E. Lopez Cabarcos. Loading and release of doxycycline hyclate from strontium-substituted calcium phosphate cement, Acta Biomaterialia 6 (2010) 1522-1528.

[15] F. Matthew, Reeves, A. Patricia, Lohr, L. Jennifer, Hayes, J. Bryna, Harwood, D. Mitchell, Creinin, Doxycycline serum levels at the time of dilation and evacuation with two dosing regimens, Contraception 79 (2009) 129-133

[16] Q. Wang, Z. Dong, Y. Du and J.F. Kennedy, Controlled release of ciprofloxacin hydrochloride from chitosan/polyethylene glycol blend films, Carbohydrate Polymers 69 (2007)336-343.

[17] H.M. Nizam El-Din, Characterization and caffeine release properties of Nisopropylacrylamide/ hydroxypropyl methacrylate copolymer hydrogel synthesized by gamma radiation, J. Appl. Polym. Sci. 119 (2011) 577-585.

[18] H.M. Nizam El-Din and A.M El-Naggar, Characterization of gamma irradiated concentrated aqueous solutions of chitosan/sodium alginate blends and their drug uptake-release characters, J. App.1 Polym. Sci. 122 (2011) 2383-2390.

[19] H.M. Nizam El-Din, S.G. Abd Alla and A.M. El-Naggar, Swelling and drug release properties of acrylamide/carboxymethyl cellulose networks formed by gamma irradiation, Radiation Physics and Chemistry 9(2010) 725-730.

[20] C. Liu, Y. Chen, and J. Chen, Synthesis and characteristics of pH-sensitive semiinterpenetrating polymer network hydrogels based on konjac glucomannan and poly (aspartic acid) for in vitro drug delivery. Carbohydrate Polymers 79 (2010) 500-506.

[21] G. Tamasi, F. Serinelli, M. Consumi, A. Magnani, M. Casolaro and R. Cini, Release studies from smart hydrogels as carriers for piroxicam and copper (II) oxicam complexes as anti-inflammatory and anti-cancer drugs: X-ray structures of 
Military Technical College

Kobry El-Kobbah,

Cairo, Egypt

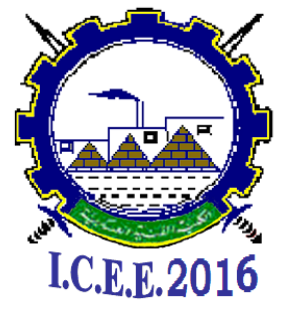

$8^{\text {th }}$ International Conference

on

Chemical \& Environmental Engineering

$19-21$ April 2016

new copper (II) piroxicam and isoxicam complex molecules. Journal of Inorganic Biochemistry 102(2008) 1862-1873.

[22] B. Tas-delena, N. Kayaman-Apohanb, O. Guvenc and B.M. Baysald, Anticancer drug release from poly(N-isopropylacrylamide/itaconic acid) copolymeric hydrogels. Radiation Physics and Chemistry 73 (2005) 340-345.

[23] A. Kishida and Y. Ikada, Hydrogels for Biomedical and Pharmaceutical Applications. In Dumitriu S, Editor "Polymeric Biomaterials", 2nd ed., p. (2002). $133-45$.

[24] A. Chapiro, Radiation Chemistry of Polymeric Systems; Interscience: New York, 22-81, (1962).

[25] S.G. Abd Alla, H.M. Nizam El-Din and A.M. El-Naggar, Electron Beam Synthesis and Characterization of Poly(vinyl alcohol)/ Montmorillonite Nanocomposites, J Appl Polym Sci. 102 (2006)1129.

[26] J. Michael, Mc Gann, L. Clement, Higginbotham, M. Luke, Geever, J.D. Michael, and Nugent, The synthesis of novel $\mathrm{pH}$-sensitive poly(vinyl alcohol) composite hydrogels using a freeze/thaw process for biomedical applications, International Journal of Pharmaceutics 372 (2009) 154-161.

[27] Q. Wang, J. Zhang and A. Wang, Preparation and characterization of a novel pHsensitive chitosan-g-poly (acrylic acid)/attapulgite/sodium alginate composite hydrogel bead for controlled release of diclofenac sodium. Carbohydrate Polymers 78(2009) 731-737.

[28] N.A. Peppas, R. Gurny, E. Doelker, and D. Buri, Modelling of drug diffusion through swellable polymeric, Journal of Membrane Science 7(1989) 241. 
Military Technical College Kobry El-Kobbah, Cairo, Egypt

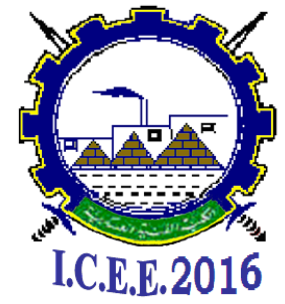

$8^{\text {th }}$ International Conference on

Chemical \& Environmental Engineering

19 - 21 April 2016

Table 1: Kinetic parameters of Doxycycline hyclate drug release, at room temperature $(\mathrm{pH}=7)$, from PVA/MC $(95 / 5 \%)$ blends prepared at different doses of gamma irradiation.

\begin{tabular}{|l|l|l|l|}
\hline Dose $(\mathrm{kGy})$ & $\mathrm{n}$ & $\mathrm{k} \mathrm{x} \mathrm{10}$ & $\mathrm{r}^{2}$ \\
\hline 5 & 1.073 & 2.926 & 0.99314 \\
\hline 10 & 1.060 & 3.336 & 0.96343 \\
\hline 30 & 0.991 & 4.706 & 0.97324 \\
\hline 40 & 0.760 & 15.733 & 0.99625 \\
\hline
\end{tabular}

Table 2: Kinetic parameters of Doxycycline hyclate drug release, at room temperature at different $\mathrm{pH}$ values, from $\mathrm{PVA} / \mathrm{MC}$ blends prepared, gamma irradiated at a dose $30 \mathrm{kGy}$.

\begin{tabular}{|l|l|l|l|l|}
\hline PVA/MC (\%) blends & $\mathrm{pH}$ & $\mathrm{n}$ & $\mathrm{k}$ & $\mathrm{r}^{2}$ \\
\hline $95 / 5 \%$ & 3 & 0.83 & 0.009 & 0.969324 \\
\cline { 2 - 5 } & 9 & 0.63 & 0.027 & 0.976761 \\
\hline \multirow{2}{*}{$90 / 10 \%$} & 3 & 0.87 & 0.127 & 0.958268 \\
\cline { 2 - 5 } & 9 & 0.75 & 0.0136 & 0.942407 \\
\hline
\end{tabular}

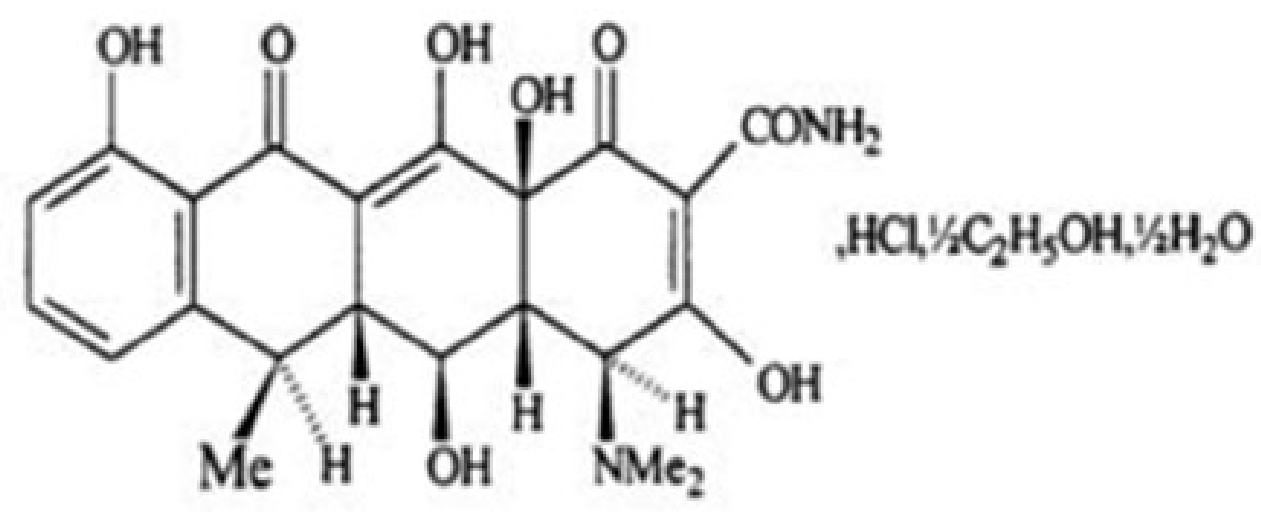

Fig.1.Chemical structure of Doxycycline hyclate (DOX-h) drug 
Military Technical College Kobry El-Kobbah, Cairo, Egypt

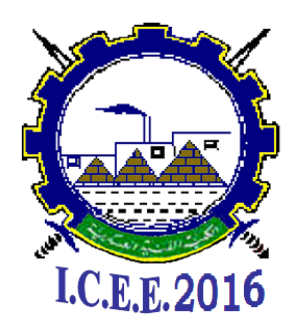

$8^{\text {th }}$ International Conference on Chemical \& Environmental Engineering $19-21$ April 2016

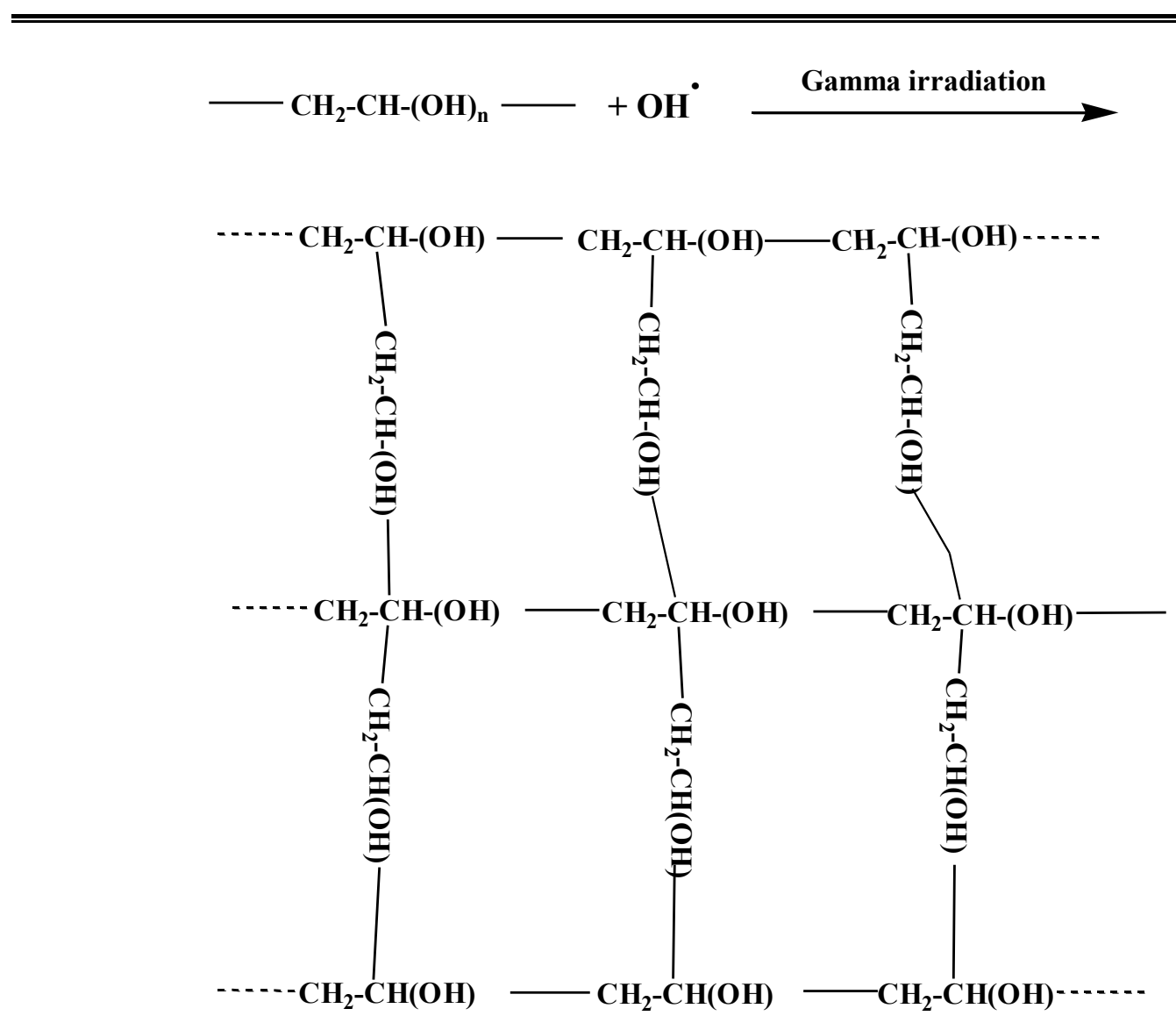

Fig.2. Schematic diagram of gamma- radiation induced crosslinking of PVA. 
Military Technical College Kobry El-Kobbah, Cairo, Egypt

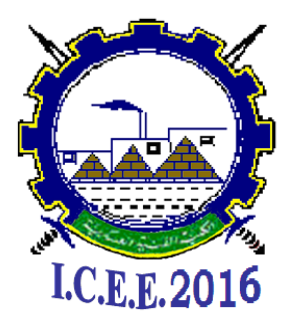

$8^{\text {th }}$ International Conference on Chemical \& Environmental Engineering $19-21$ April 2016
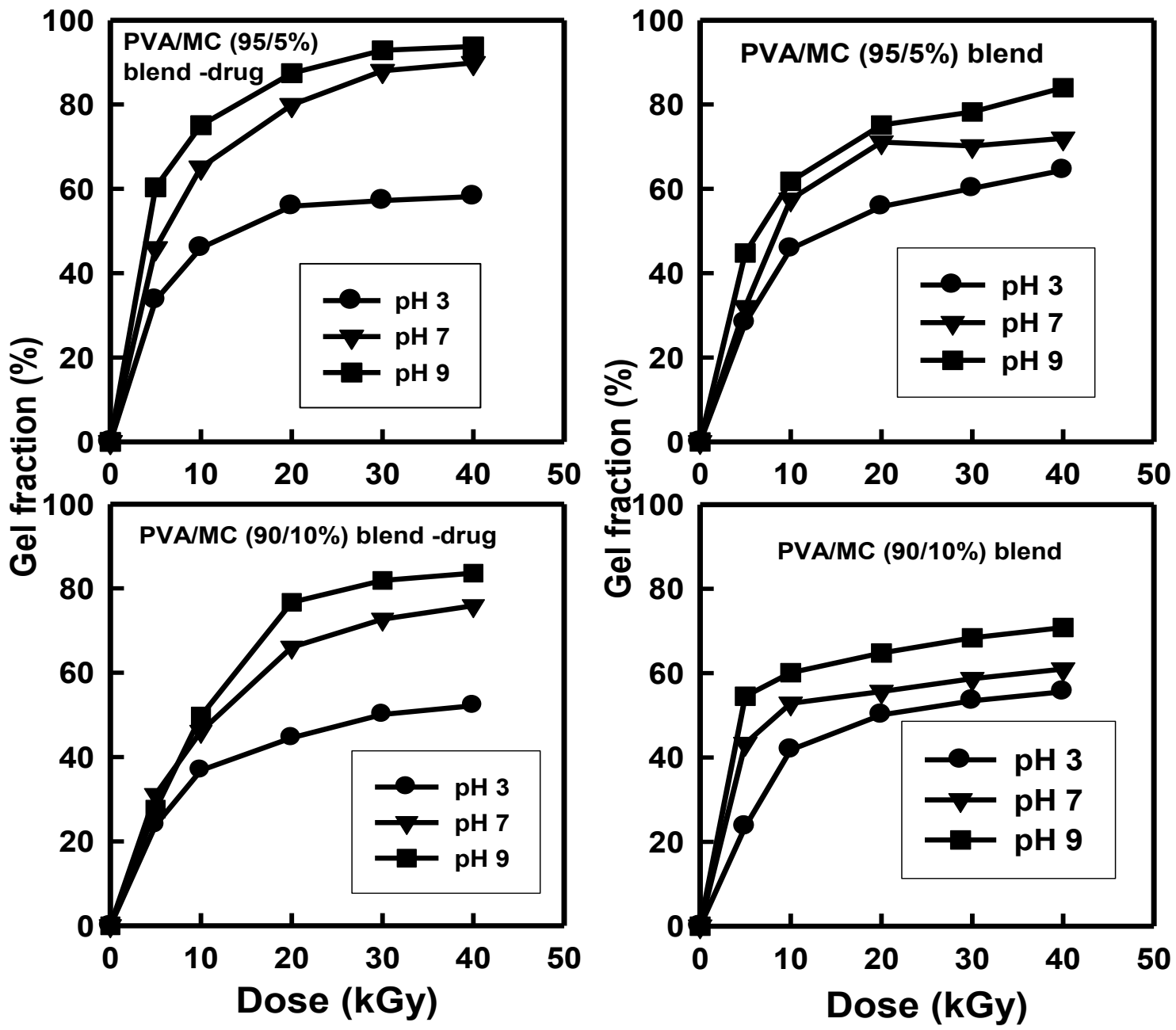

Fig.3. Gel fraction of PVA/MC blends loaded with $1 \%$ of (DOX-h) drug and PVA/MC blends free of drug, measured at different $\mathrm{pH}$ values, gamma irradiated at different doses. 
Military Technical College Kobry El-Kobbah, Cairo, Egypt

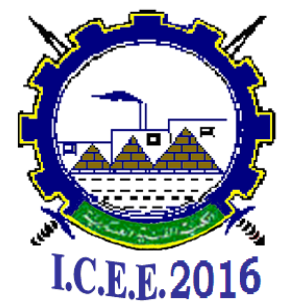

$8^{\text {th }}$ International Conference on Chemical \& Environmental Engineering 19-21 April 2016
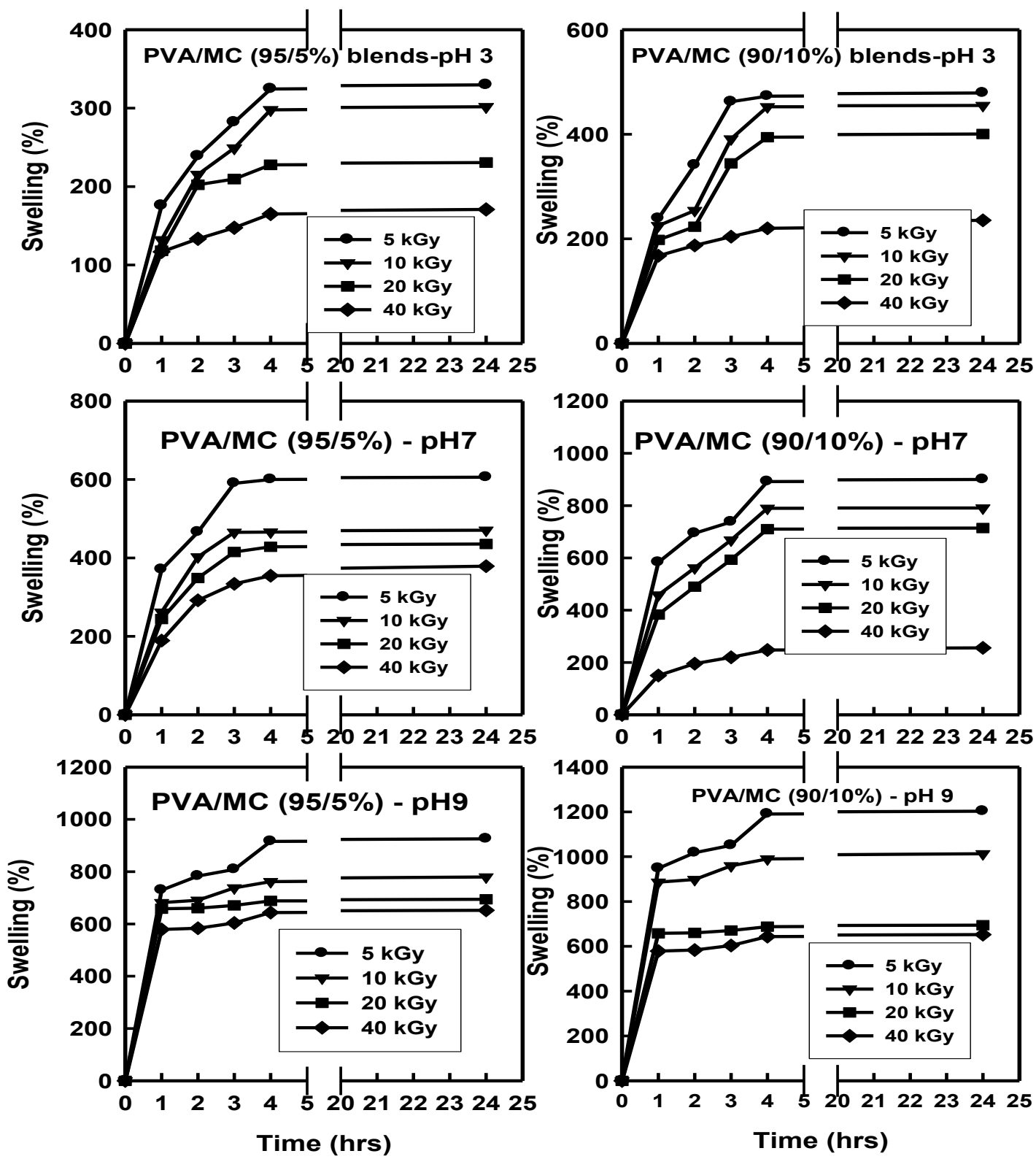

Fig.4. Swelling (\%) measured at different pH values of PVA/MC (95/5\%) blends, gamma irradiated at different doses. 
Military Technical College Kobry El-Kobbah, Cairo, Egypt

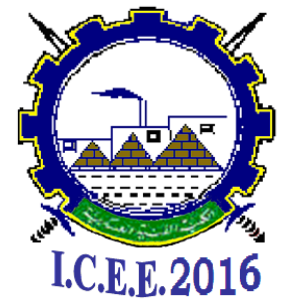

$8^{\text {th }}$ International Conference on Chemical \& Environmental Engineering $19-21$ April 2016
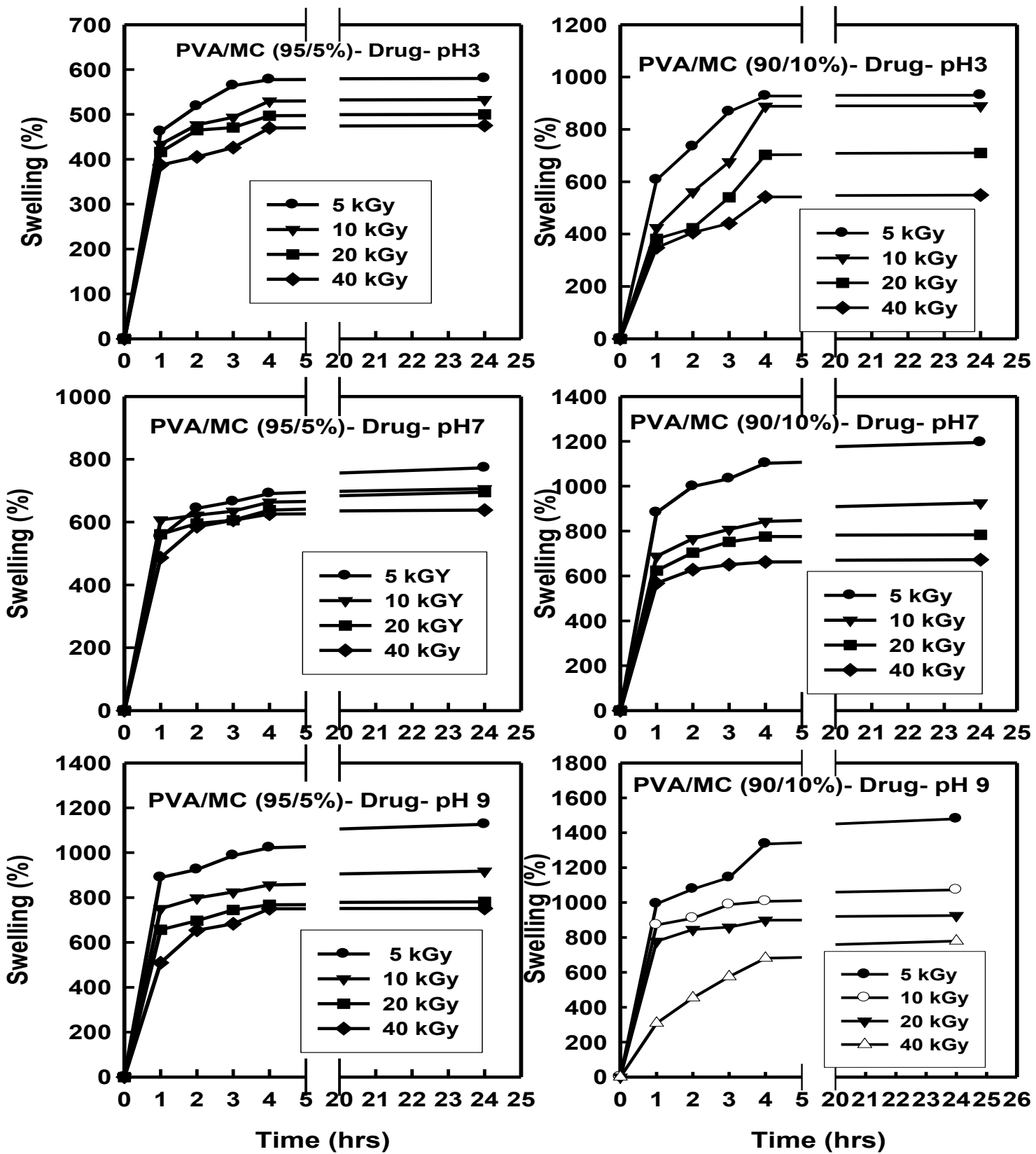

Fig.5. Swelling (\%) measured at different pH values of PVA/MC (95/5\%) blends, before and after loading with $1 \%$ of (DOX-h) drug, gamma irradiated at different doses. 
Military Technical College Kobry El-Kobbah, Cairo, Egypt

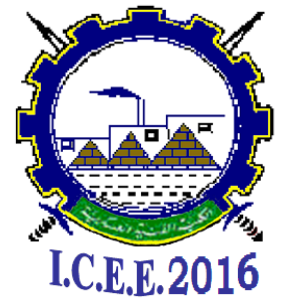

$8^{\text {th }}$ International Conference on Chemical \& Environmental Engineering

$19-21$ April 2016

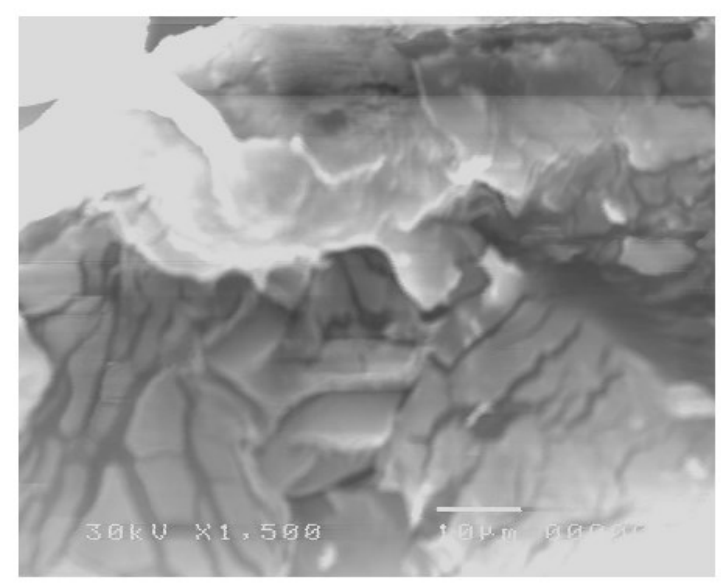

95/5\%- 0 kGy

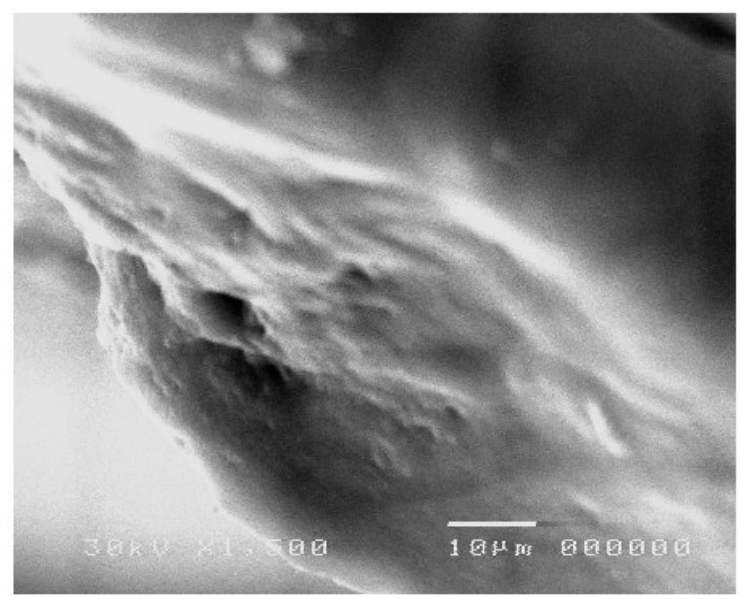

95/5\%- 20 kGy- drug

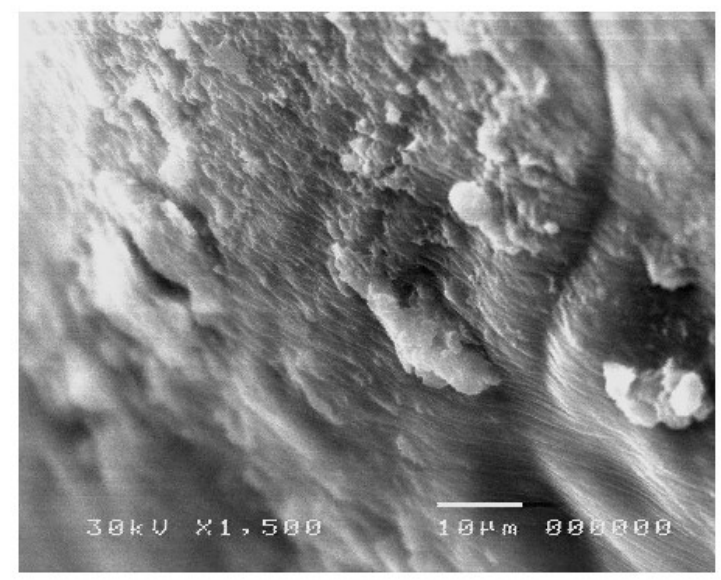

95/5\%- 0 kGy- drug

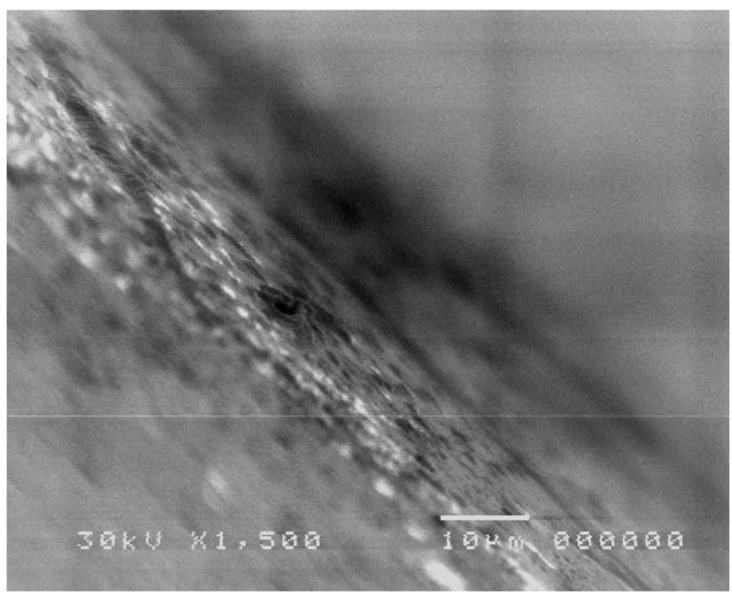

95/5\%- 40 kGy- drug

Fig.6-a. SEM micrographs of different ratios of PVA/MC blends loaded with $1 \%$ of (DOX-h) drug, gamma irradiated at different doses. 
Military Technical College Kobry El-Kobbah, Cairo, Egypt

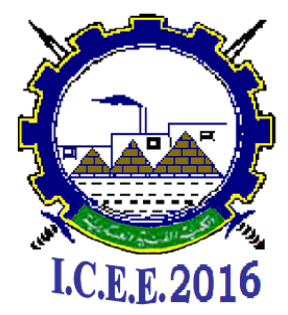

$8^{\text {th }}$ International Conference on

Chemical \& Environmental Engineering

$19-21$ April 2016

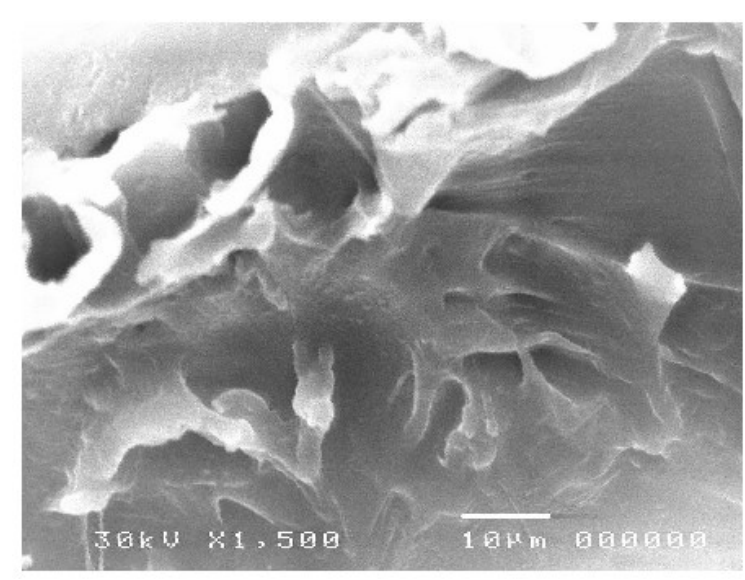

90/10\%- 0 kGy

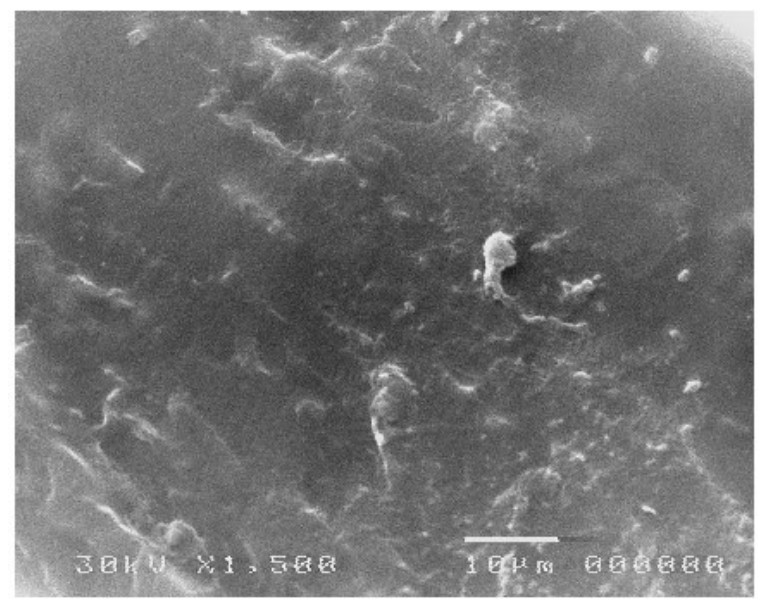

90/10\%- 20 kGy- drug

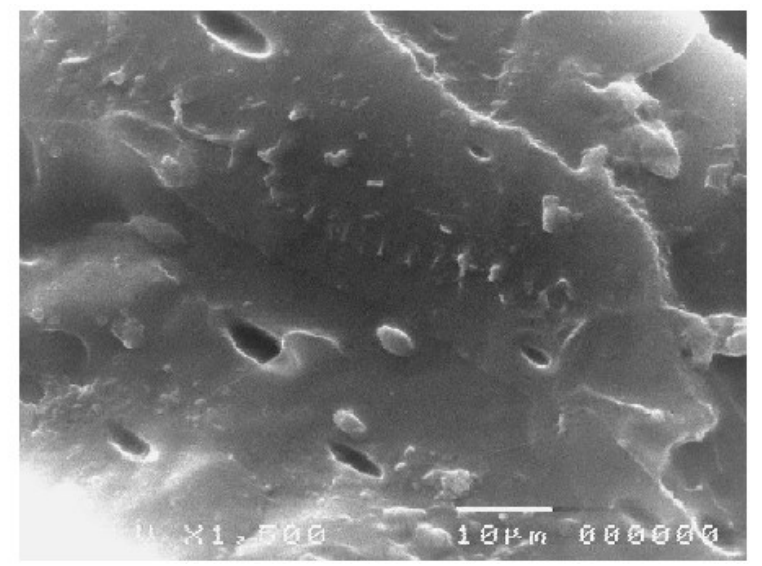

90/10\%- 0 kGy- drug

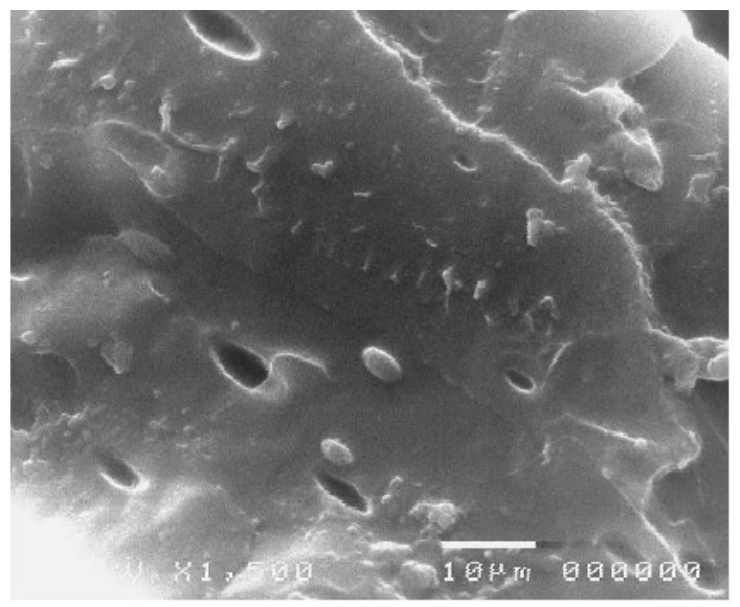

90/10\%- 0 kGy- drug

Fig.6-b. SEM micrographs of different ratios of PVA/MC blends loaded with $1 \%$ of (DOX-h) drug, gamma irradiated at different doses. 
Military Technical College Kobry El-Kobbah, Cairo, Egypt

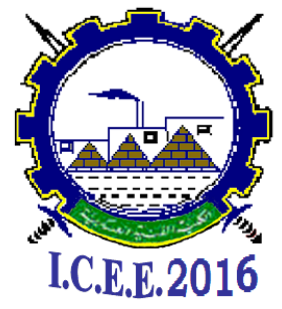

$8^{\text {th }}$ International Conference on

Chemical \& Environmental Engineering

$19-21$ April 2016

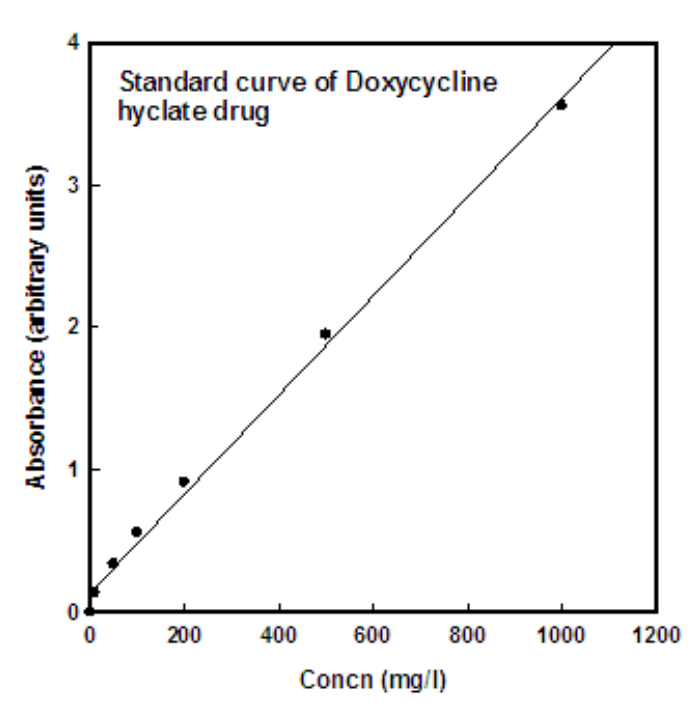

Fig.7. Calibration curve representing absorbance of different concentrations of the Doxycycline hyclate (DOX-h ) drug.

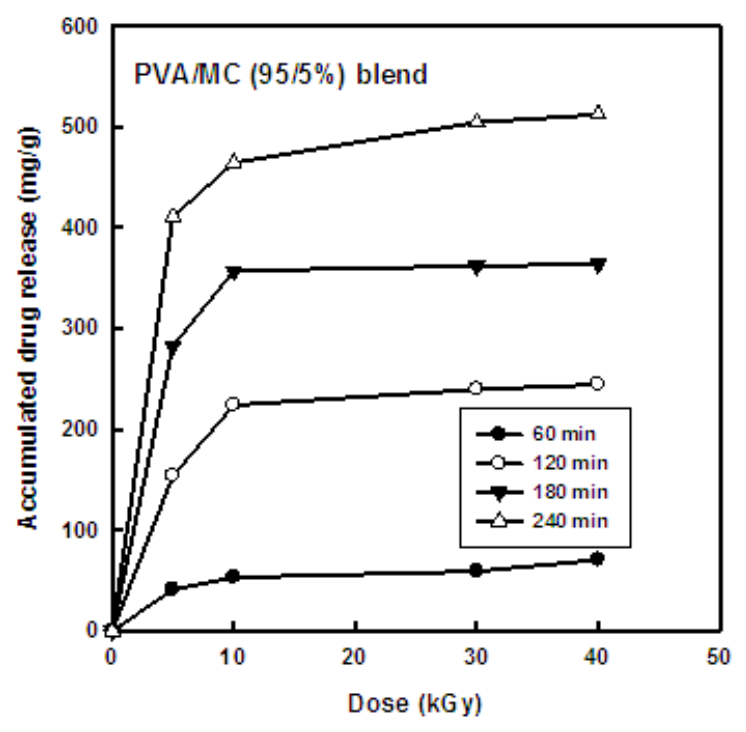

Fig.8. Accumulated release of DOX drug, at room temperature and $\mathrm{pH} 7$, at different time intervals, from PVA/MC (95/5\%) blends, gamma irradiated at different doses. 
Military Technical College Kobry El-Kobbah, Cairo, Egypt

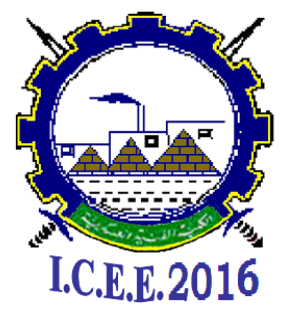

$8^{\text {th }}$ International Conference on

Chemical \& Environmental Engineering

19 - 21 April 2016

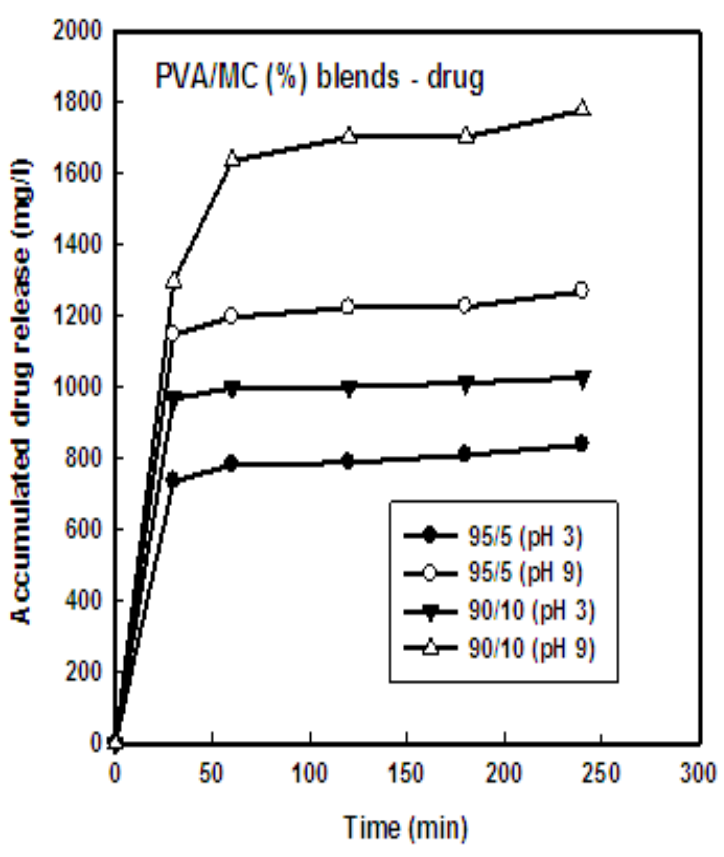

Fig.9. Accumulated release of DOX-h drug, at room temperature and different $\mathrm{pH}$ values, from PVA/MC blends, gamma irradiated at a dose of 30 kGy.

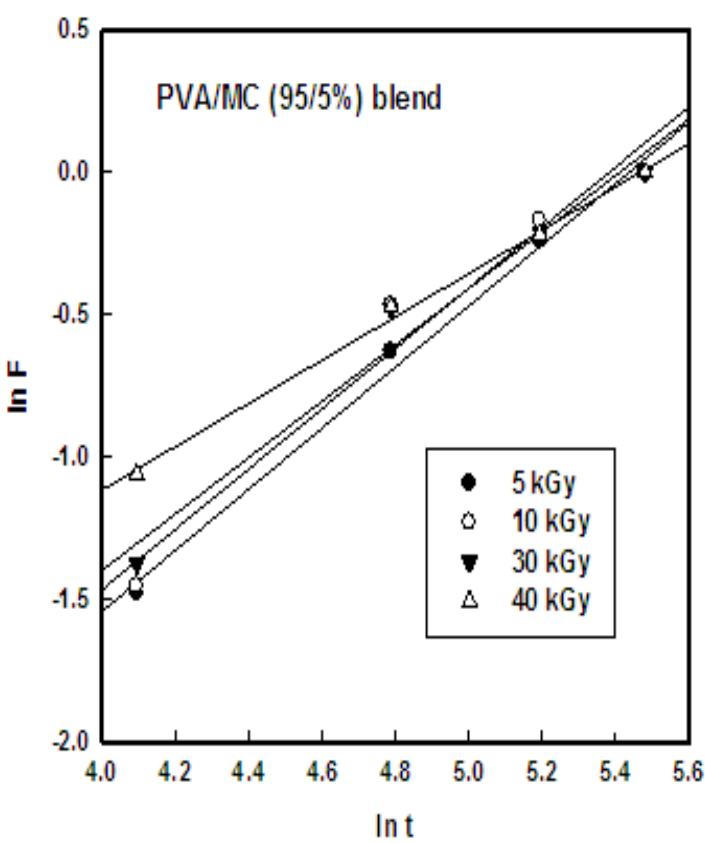

Fig.10. In $F$ against In $t$ plots for the release of $\mathrm{DOX}-\mathrm{h}$ drug from PVA/MC (95/5\%) blends, gamma irradiated at different doses. 
Military Technical College Kobry El-Kobbah, Cairo, Egypt

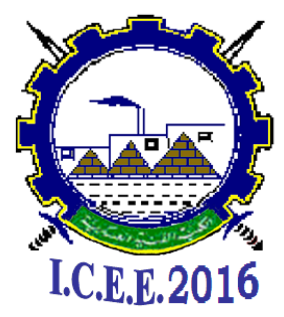

$8^{\text {th }}$ International Conference on

Chemical \& Environmental Engineering

$19-21$ April 2016

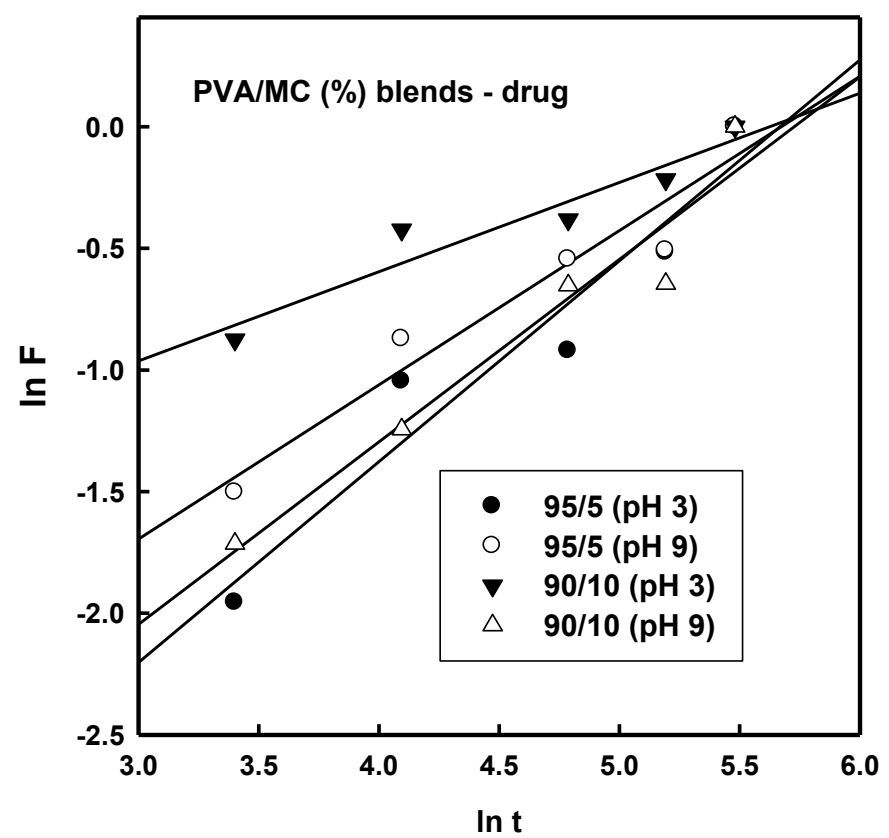

Fig.11. In F against In t plots for the release of DOX-h drug from PVA/MC blends at different $\mathrm{pH}$ values, gamma irradiated at a dose of $30 \mathrm{kGy}$. 